\title{
The Effect of the State of the Indoor Environment on the Air Quality in the Cabin
}

\author{
Zuzana Kolková ${ }^{1}$, Peter Hrabovský1, Jozef Matušov ${ }^{1}$, Lenka Mikulová1, Luboš Daniel ${ }^{1}$ \\ ${ }^{1}$ University of Žilina, Research centre \\ Univerzitná 8215/1, Žilina, Slovakia \\ zuzana.kolkova@uniza.sk; peter.hrabovsky@uniza.sk; jozef.matusov@uniza.sk; lenka.mikulova@uniza.sk; \\ lubos.daniel@uniza.sk
}

\begin{abstract}
Air quality affects the state of the environment, human health as well as individual ecosystems to a significant extent. The permissible level of air pollution is determined by the national laws of each country and the EU. Air quality problems are related to the amount of pollutant emissions that escape into the atmosphere. These emissions have different origins. Transport is identified as one of the serious problems of the future also in terms of air pollution, especially in view of the rising trend of final energy consumption in road transport. One of the main factors of deteriorating air quality in the urban environment is burdened by high traffic density. Regulation of emissions from transport, including passenger cars, is in the general interest of European legislation. Transport produces almost a quarter of Europe's greenhouse gas emissions and is a major cause of urban air pollution. At the same time, it is necessary to deal with air quality in cars, which is affected by several factors. The aim of this article is to analyse the air quality in the cabin of a car that uses a pollen filter with activated carbon. The analysis is focused on particles from 0.3 to $10 \mu \mathrm{m}$ in 16 size categories that affect the health of people in the car. The influence of the fan setting and the state of the indoor environment on the particle concentrations will also be evaluated.
\end{abstract}

Keywords: car interior, air pollution, concentration, mass, aerosol

\section{Introduction}

Zulauf, Droege, Klingelhoefer, Braun, Oremek, Groneberg report that people spend an average of 45 minutes in vehicles. In Germany alone, the number of cars has increased to around 43 million household vehicles. This means that each household has, on average, more than one car to use [1]. The study by Mueller, Klingelhoefer, Uibel, Groneberg states that the population of industrialized countries, such as the United States or the European Union, spends approximately more than an hour a day in vehicles. The authors summarized studies that deal with particulate exposure and offer a complete overview of indoor air pollution [2]. The Swiss company IQAir states that the air in cars can be up to 15 times worse than just a few meters away. The worst exposure is when the car is standing in a column waiting for the others to move [3]. Professor Jung at UC Riverside is researching how external pollution gets into cars. Its aim is to identify ways to improve air quality in the car cabin. They tested 100 vehicles and created a database to help drivers protect their health. Closing the windows and choosing the circulation using the car's ventilation reduces the concentration of solid particles. Low ventilator recirculation removes most of the ultrafine nanoparticles, which are particularly good for penetrating the human lung [4, 5]. Barnes, Ng, Ma, Lai assess car air quality while driving in air-conditioned vehicles in Hong Kong. They performed complete measurements on 51 vehicles. They have developed assessments and tips to reduce emissions inside the car [6]. People are exposed to cars with concentrations of particles below PM2.5, which are harmful to health. Emissions are a current and debated issue in the world. Car manufacturers are already dealing with this problem. Volvo car manufacturers have come up with in-car air purification technology. The new technology comes with a sensor that measures the levels of PM2.5 solids inside the cab. The PM 2.5 particulate value indicates the amount of particulate matter in the air and is often used to measure air quality. Many urban areas around the world exceed PM 2.5 levels recommended by the World Health Organization, which emphasizes the need to minimize their impact. Thanks to the filter based on synthetic fibers and ionization, it removes up to 95 percent of all PM 2.5 particles from the cab. This optimizes the air quality inside the vehicle and reduces the adverse health effects associated with air pollution and particulate matter. Cleaner air inside the vehicle also contributes to safer driving, as healthy and fresh air can help increase driver concentration [7]. This trend will continue. However, it is a solution for new cars. It is important to examine the condition of older types and provide optimal and feasible solutions to protect the health of all people 


\section{Air Pollutants in the Car Cabin}

Kumar stated causes a higher concentration of pollutants inside the car than in the external environment in their studies. This is due to the fact that emissions from surrounding vehicles penetrate inside cars. The authors present the results of studies that have shown that up to half of the pollutants in the cabs of cars come from vehicles that drive before the name. Vehicles are not airtight and these emissions penetrate through various openings and leaks into the cab [8].

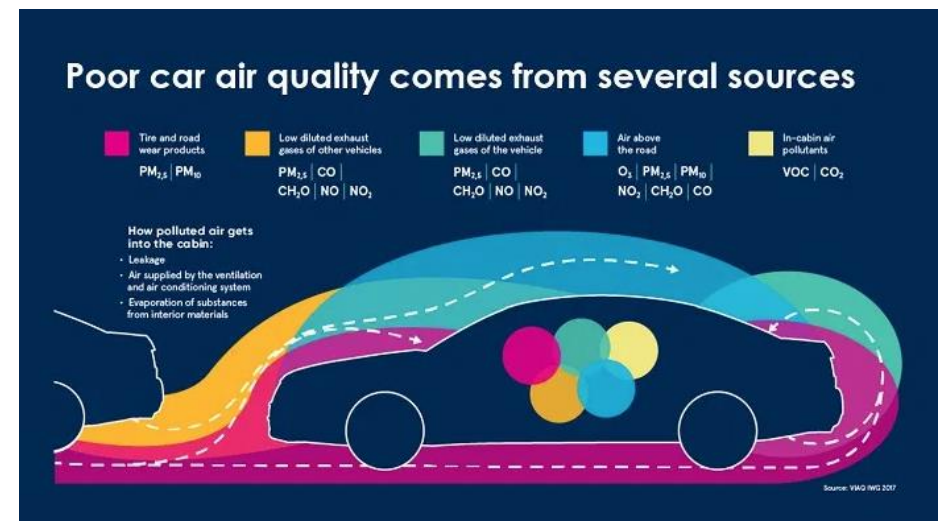

Fig. 1: Several sources of air pollution [9]

Atmospheric aerosols consist of primary particles emitted directly from terrestrial and marine sources and secondary particles formed by chemical reactions in the atmosphere. Chemical compositions of particles are different depending on aerosol size. Fine particles with diameter less than $2.5 \mu \mathrm{m}$ (usually called PM2.5) contain primary particles, from combustion of fossil fuels and biofuels, and secondary particles formed in the atmospheric reactions, while course particles with diameter 2.5-10 $\mu \mathrm{m}$ (PM10-2.5) contain mineral dust from Earth crustal rocks and soil, sea salt from ocean, and fly ash from coal combustion. Chemical composition of atmospheric aerosols is broadly classified into inorganic and organic compounds. The inorganic components include mineral dust, elemental carbon such as soot, sea salt, and water-soluble ions formed from gaseous molecules, SO2, NOx, and NH3. The organic compounds include primary species emitted by biomass and fossil fuel combustion and secondary components formed by chemical reaction of volatile organic compounds (VOCs) from natural and anthropogenic origin [10].

\section{Experiment Setup}

8 basic settings were measured. The car was parked in the city, next to the main road with heavy traffic. Each measurement started in the M1 - outside air mode, which is a measurement of the air quality outside the car. Subsequently, the device was placed in the cab of the car and the measurement of M2 - car stop began, the quality of the car's interior air was measured, when the car was parked in the parking lot and the engine was turned off, the car door was closed. Then the engine was started and the car was driving in the city during the whole measurement. The city has more than 81,000 inhabitants. The measurement took place in the afternoon, when there is heavy traffic. The route of the car was chosen through the centre and the largest intersection, where a high concentration of pollutants is expected. Subsequently, measurements M3 - drive V0, the fan in the cabin was switched off, M4 - drive, V1 - the fan was in position 1, M5 - drive, V2 - the fan in position V2, M6 - drive, V3 - the fan in position V3, M7- drive, V4 - fan in position V4, which is maximum power. To compare the quality of outdoor air, the air condition was also measured in a village $30 \mathrm{~km}$ from the city with a population of about $1200-\mathrm{M} 8$. The measurement took place in April, which was cold weather and the inhabitants of the village were already heating houses. There is gas in the village, which is available to almost all residents, but during this period, solid fuel combustion equipment is used to a large extent for heating in the afternoon. In our basic measurement, a diesel car with a pollen filter with activated carbon is used. The number of kilometers driven on the filter is 5000. In general, the filter is used for about $20 \%$ of the recommended service life. Air quality is also affected by the cleanliness of the car, which is why we evaluate air quality for two basic settings. The first 
setting is the interior cabin is not clean, the service life is 1 month. The second setting is immediately after cleaning the interior of the car.
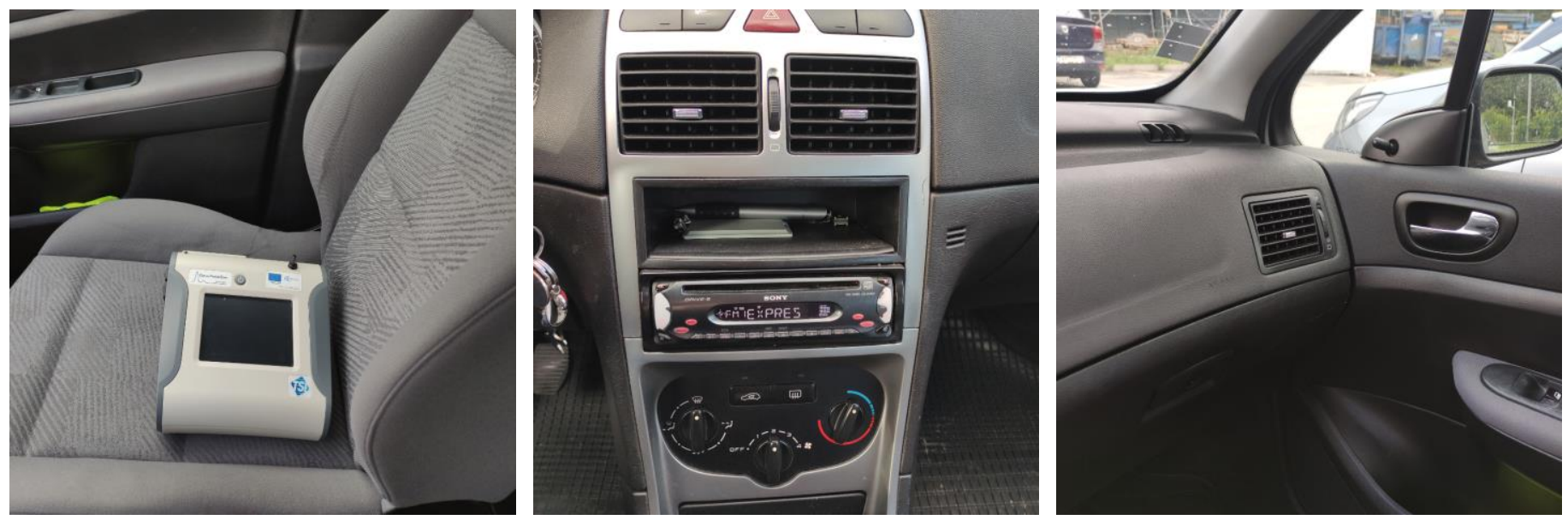

Fig. 2: Several sources of air pollution [9]

An optical particle counter is used to measure the concentration of particles in the interior of a car. The TSI Model 3330 OPS spectrometer is a high performance, general-purpose particle spectrometer that measures aerosol optical diameter. The Model 3330 provides accurate count size distributions for particles with optical diameters from 0.3 to 10 micrometers. The OPS3330 operates on the principle of single particle counting. The OPS uses a laser and a detector to detect particles passing through a sensing volume illuminated by the laser. The flow rate being sampled in to the instrument is $1.0 \mathrm{~L} / \mathrm{min}$. Aerosol is drawn into the inlet and is immediately surrounded by sheath flow that is provided from the exhaust of the pump. The sheath flow is filtered and monitored by the pump. The sheath flow is monitored by measuring the pressure drop through an orifice. This pressure drop is converted by the firmware to a volumetric flow with compensation for absolute atmospheric pressure. After passing through the orifice, the sheath flow is directed to the optics chamber where it surrounds the sample flow. The OPS measures particle concentration by counting individual pulses from the photodetector. This works well when particle concentrations are low, but when particle concentrations are high, pulses start to overlap each other [11].

\section{Results}

The measurement was performed for two basic settings in the car. In the first step, we chose a change of state that can be influenced by everyone. One of the main conditions that we can influence is the cleanliness of the car's interior. This fact also contributes to the protection of human health. We evaluated the state of use of the car without cleaning for 1 month. After a series of first measurements, the car was cleaned in the standard way, vacuuming, beating and washing the car interior. We chose the passenger seat, which is the most frequently occupied seat in the car after the driver's seat. The measurement results are the average of the 5 minute intervals for each measurement. After each measurement, a certain time was chosen to stabilize the conditions of the given setting. Table 1. shows the results that assess the condition if the car is not clean. Table 2. shows the results for a clean interior. Particle size distribution measured inside the cabin were analysed based on mobile measured PM value. The windows on the car were closed throughout the measurement and car does not have air conditioning. The M1 measurement defines the state of the outside air in the car. M2-car stop is the state of the air in the car after 8 hours of parking in the parking lot. Particle concentrations up to 1,007 $\mu \mathrm{m}$ differ only slightly and the state of the air is almost the same. The differences arise towards higher particle sizes, which is caused by the flow of outside air and the condition of the car's interior. The car started starting at the V0 fan position, i.e. the fan is switched off.

Table 1: Measurement - without interior cleaning 


\begin{tabular}{|c|c|c|c|c|c|c|c|c|}
\hline Setup & $\mathbf{M 1}$ & M2-car stop & M3-V0 & M4-V1 & M5-V2 & M6-V3 & M7-V4 & M8-village \\
\hline Size $\mathbf{\mu m}$ & $\# / \mathrm{cm}^{\mathbf{3}}$ & $\# / \mathrm{cm}^{\mathbf{3}}$ & $\# / \mathrm{cm}^{\mathbf{3}}$ & $\# / \mathrm{cm}^{\mathbf{3}}$ & $\# / \mathrm{cm}^{\mathbf{3}}$ & $\# / \mathrm{cm}^{3}$ & $\# / \mathrm{cm}^{3}$ & $\# / \mathrm{cm}^{3}$ \\
\hline $\mathbf{0 , 3 3 7}$ & 212,4 & 213,4 & 215,3 & 207,8 & 223,5 & 210,9 & 331,9 & 264,2 \\
\hline $\mathbf{0 , 4 1 9}$ & 53,7 & 53,9 & 54,2 & 58,7 & 59,6 & 58,9 & 117,2 & 65,6 \\
\hline $\mathbf{0 , 5 2 2}$ & 14,8 & 15,3 & 16,4 & 17,7 & 17,0 & 17,1 & 41,3 & 16,3 \\
\hline $\mathbf{0 , 6 5}$ & 4,61 & 5,43 & 5,42 & 5,96 & 5,51 & 5,91 & 14,4 & 4,87 \\
\hline $\mathbf{0 , 8 0 9}$ & 1,73 & 2,00 & 2,50 & 2,30 & 2,27 & 1,99 & 5,82 & 2,20 \\
\hline $\mathbf{1 , 0 0 7}$ & 2,62 & 3,62 & 4,61 & 4,37 & 4,12 & 3,94 & 5,80 & 2,63 \\
\hline $\mathbf{1 , 2 5 4}$ & 0,821 & 1,21 & 1,73 & 1,60 & 1,30 & 1,04 & 1,66 & 1,05 \\
\hline $\mathbf{1 , 5 6 2}$ & 0,706 & 1,14 & 2,05 & 1,44 & 1,21 & 0,938 & 1,10 & 0,97 \\
\hline $\mathbf{1 , 9 4 4}$ & 0,97 & 2,11 & 2,68 & 1,76 & 1,60 & 1,28 & 0,909 & 1,49 \\
\hline $\mathbf{2 , 4 2 1}$ & 0,632 & 1,42 & 1,77 & 1,21 & 0,769 & 0,642 & 0,517 & 1,23 \\
\hline $\mathbf{3 , 0 1 4}$ & 0,411 & 0,801 & 0,938 & 0,643 & 0,432 & 0,20 & 0,201 & 0,896 \\
\hline $\mathbf{3 , 7 5 2}$ & 0,158 & 0,717 & 0,548 & 0,369 & 0,19 & 0,126 & 0,116 & 0,696 \\
\hline $\mathbf{4 , 6 7 2}$ & $8,43 \mathrm{E}-02$ & 0,601 & 0,316 & 0,158 & $6,32 \mathrm{E}-02$ & $6,32 \mathrm{E}-02$ & $5,28 \mathrm{E}-02$ & 0,527 \\
\hline $\mathbf{5 , 8 1 6}$ & $7,38 \mathrm{E}-02$ & 0,316 & 0,105 & 0,105 & $2,11 \mathrm{E}-02$ & $1,05 \mathrm{E}-02$ & $7,40 \mathrm{E}-02$ & 0,38 \\
\hline $\mathbf{7 , 2 4 1}$ & $6,33 \mathrm{E}-02$ & 0,285 & $6,33 \mathrm{E}-02$ & $4,22 \mathrm{E}-02$ & $4,22 \mathrm{E}-02$ & $0,00 \mathrm{E}+00$ & $5,28 \mathrm{E}-02$ & 0,359 \\
\hline $\mathbf{9 , 0 1 5}$ & $4,21 \mathrm{E}-02$ & 0,263 & $7,37 \mathrm{E}-02$ & 0,00 & $1,05 \mathrm{E}-02$ & $0,00 \mathrm{E}+00$ & $1,06 \mathrm{E}-02$ & 0,242 \\
\hline
\end{tabular}

Table 2: Measurement - with interior cleaning

\begin{tabular}{|c|c|c|c|c|c|c|c|c|}
\hline Setup & M1-1 & M2-1car stop & M3-1, V0 & M4-1,V1 & M5-1,V2 & M6-1,V3 & M7-1,V4 & M8-1,village \\
\hline Size $\mu \mathrm{m}$ & $\# / \mathrm{cm}^{3}$ & $\# / \mathrm{cm}^{3}$ & $\# / \mathrm{cm}^{3}$ & $\# / \mathrm{cm}^{3}$ & $\# / \mathrm{cm}^{3}$ & $\# / \mathrm{cm}^{3}$ & $\# / \mathrm{cm}^{3}$ & $\# / \mathrm{cm}^{3}$ \\
\hline 0,337 & 335,2 & 304,4 & 295,6 & 355,8 & 283,4 & 270,5 & $1,04 E+03$ & $1,35 E+03$ \\
\hline 0,419 & 101,8 & 85,3 & 84,3 & 98,6 & 83,1 & 83,7 & 201,8 & 349,1 \\
\hline 0,522 & 24,9 & 21,3 & 19,8 & 27,9 & 21,2 & 25,1 & 49,8 & 59,2 \\
\hline 0,65 & 5,26 & 4,03 & 4,07 & 7,39 & 5,42 & 7,36 & 11,5 & 10,9 \\
\hline 0,809 & 1,43 & 0,995 & 1,10 & 3,19 & 1,51 & 2,85 & 4,22 & 2,48 \\
\hline 1,007 & 1,14 & 1,52 & 1,32 & 7,52 & 2,88 & 5,84 & 8,96 & 2,18 \\
\hline 1,254 & 0,338 & 0,401 & 0,569 & 2,67 & 1,08 & 2,48 & 2,96 & 0,534 \\
\hline 1,562 & 0,369 & 0,327 & 0,348 & 2,68 & 0,823 & 1,88 & 2,47 & 0,524 \\
\hline 1,944 & 0,317 & 0,412 & 0,296 & 4,00 & 1,33 & 2,74 & 3,14 & 0,332 \\
\hline 2,421 & 0,169 & 0,285 & 0,232 & 2,66 & 0,98 & 1,40 & 1,54 & 0,214 \\
\hline 3,014 & 6,33E-02 & 0,211 & 0,2 & 1,32 & 0,464 & 0,359 & 0,426 & 0,203 \\
\hline 3,752 & $5,28 \mathrm{E}-02$ & 0,137 & 0,211 & 0,655 & 0,232 & 0,179 & 0,149 & 0,15 \\
\hline 4,672 & $2,11 \mathrm{E}-02$ & 0,19 & 0,222 & 0,359 & 0,211 & $3,17 \mathrm{E}-02$ & $6,39 \mathrm{E}-02$ & 0,139 \\
\hline 5,816 & $1,06 \mathrm{E}-02$ & 0,116 & 0,201 & 0,127 & 0,127 & $2,11 \mathrm{E}-02$ & $2,13 \mathrm{E}-02$ & 0,150 \\
\hline 7,241 & $1,06 \mathrm{E}-02$ & 0,169 & 0,127 & $3,17 \mathrm{E}-02$ & $4,22 \mathrm{E}-02$ & $0,00 E+00$ & $5,28 \mathrm{E}-02$ & 0,359 \\
\hline 9,015 & $1,06 \mathrm{E}-02$ & 0,127 & 0,137 & $8,45 E-02$ & $1,05 E-02$ & $0,00 E+00$ & $1,06 \mathrm{E}-02$ & 0,242 \\
\hline
\end{tabular}

The differences in the number of concentrations between the measurements in the state of M2-car stop and M3-VO are only small and from the particle size of $3.014 \mu \mathrm{m}$ a decrease in the number of particles of higher dimensions is recorded. The results for measurements 
with the fan set to positions V1, V2 and V3 are approximately the same in the lower size classes. Changes are measured at higher sizes, where decreases occur. A significant difference occurs for the position of the V4 fan, which is the maximum power. There is a rapid increase in the number of concentrations for size classes up to $1,254 \mu \mathrm{m}$. A comparison of the influence of the condition of the interior on the concentration of parts shows that we managed to reduce the concentrations of particles above $1.007 \mu \mathrm{m}$. Conversely, the concentration of particles up to $1,007 \mu \mathrm{m}$ increased. The biggest difference is for setting V4, where the increase in particle size of 0.337 is highest. Part of the measurements of air quality in the car was also the measurement of the state of outdoor air in the city and in the village. The comparison is shown in Fig.3. The concentration of smaller particles shows small changes, but large changes for the concentrations of large particles in the village. The weather during the first measurement was partly cloudy to cloudy, average temperature $17-21{ }^{\circ} \mathrm{C}$. The weather during the second measurement was cloudy to cloudy, average temperature $7-12{ }^{\circ} \mathrm{C}$. The amount of particles with higher sizes is also caused by the burning of fossil fuels in the village.


Fig. 3: Air quality in the city (M1) and in the village (M8) $\mu \mathrm{g} / \mathrm{m}^{3}$
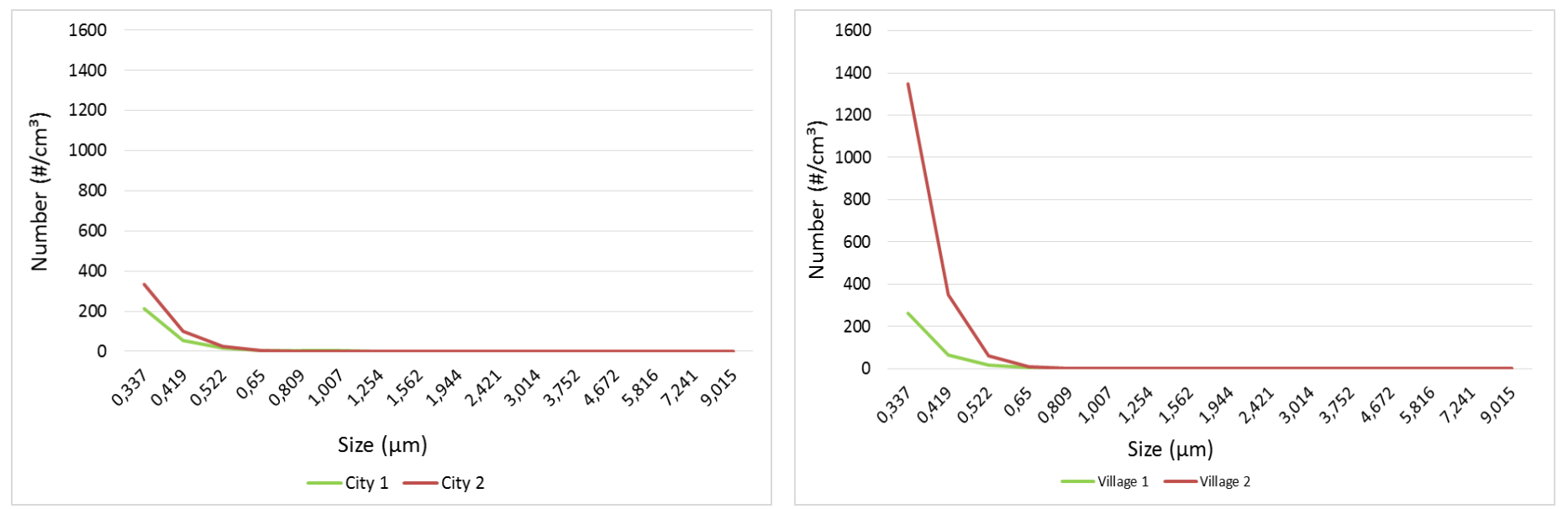

Fig. 4: Air quality in the city (M1) and in the village (M8) in $\# / \mathrm{cm}^{3}$

\section{Conclusion}

The measurements analysed the concentration of particles from 0.3 to $10 \mu \mathrm{m}$. It is interesting to observe the results for particle sizes around 2.5. This is one of the main parameters for assessing the state of the air in connection with the combustion process from cars or solid fuel boilers. This condition was also confirmed by air quality measurements in the village, where the growth of these particles is significant. For measurements in the city, the results are mainly influenced by heavy traffic and particles from the exhaust. Compared to the village, the results are much better. The presence of the smallest 
particles is higher in the car's interior than outside due to different sources of particles in the car's space. The highest concentration is again in the village. The results of measurements show mainly on the impact of burning fossil fuels, especially in municipalities. Despite the significantly lower traffic intensity, the results are worse for all monitored dimensions. In terms of assessing the condition of the interior for air quality and health protection, the particles around $\mu \mathrm{m}$ were kept at approximately the same level for the individual measurements. The change occurs at maximum fan when there is a significant increase in the number of particles. In the next step, we will analyse the impact of the quality the used pollen filter on the air quality in the car.

\section{Acknowledgements}

"This publication was realized with support of Operational Program Integrated Infrastructure 2014 - 2020 of the project: Innovative Solutions for Propulsion, Power and Safety Components of Transport Vehicles, code ITMS 313011V334, co-financed by the European Regional Development Fund" and this work was supported by Grant System of University of Zilina No. 8021. 1/2020.

\section{References}

[1] Zulauf, N., Droege, J., Klingelhoefer, D., Braun, M., Oremek, G.M., Groneberg, D.A. "Indoor Air Pollution in Cars: An Update on Novel Insights," in Int J Environ Res Public Health, 2019 Jul; 16(13): 2441. [Online]. Available: doi:10.3390/ijerph16132441

[2] Mueller, D., Klingelhoefer, D, Uibel. S., Groneberg, D.A. "Car indoor air pollution - analysis of potential sources," in Journal of Occupational Medicine and Toxicology, volume 6, Article number: 33 (2011), [Online]. Available: https://occup-med.biomedcentral.com/articles/10.1186/1745-6673-6-33

[3] IQAir "In-car air pollution," [Online]. Available: https://www.iqair.com/us/blog/air-quality/in-car-pollution

[4] Ober, H. "Clearing the air (inside your car), " [Online]. Available: https://news.ucr.edu/articles/2020/01/13/clearingair-inside-your-car

[5] Mendez-Jimenez, D., Lakey, P., Shiraiwa, M., Jung, H. "Behavior of carbon monoxide, nitrogen oxides, and ozone in a vehicle cabin with a passenger," in Environ Sci Process Impacts, 2021 Mar 4; 23(2):302-310. [Online]. Available: doi: 10.1039/d0em00395f.

[6] Barnes, N.M., Ng, T.W., Ma, K.K., Lai, K.M. "In-Cabin Air Quality during Driving and Engine Idling in AirConditioned Private Vehicles in Hong Kong," in International Journal of Environmental Research and Public Health, 2018 Mar 27;15(4):611. [Online]. Available: doi: 10.3390/ijerph15040611.

[7] Redakcia Autosuv. "Volvo prišlo s technológiou čistenia vzduchu v aute," [Online]. Available: https://www.autosuv.sk/ostatne/volvo-prislo-s-technologiou-cistenia-vzduchu-v-aute

[8] Kumar P. \& Goel A. (2016). Concentration dynamics of coarse and fine particulate matter at and around signalised traffic intersections. [Online]. Available: doi10.1039/C6EM00215C

[9] Picture 1. [Online]. Available: https://www.criticreviewer.com/blueair-cabin-car-air-purifiers-for-uae/poor-air-qualityin-the-car/

[10] Akimoto, H., Hirokawa, J., Atmospheric Multiphase Chemistry. Fundamentals of Secondary Aerosol Formation. JohnWiley \& Sons Ltd, 2020

[11] TSI OPS3330. [Online] Available: http//tsi.com/products/particle-sizers/particle-size-spectrometers/optical-particlesizer-3330/ 